\title{
Investigation of changes in the annual maximum flood in the Yellow River basin, China
}

\author{
Peng Bai, Xiaomang Liu*, Kang Liang, Changming Liu \\ Key Laboratory of Water Cycle and Related Land Surface Process, Institute of Geographic Sciences and Natural Resources Research, Chinese Academy of
} Sciences, 100101 Beijing, China

\section{A R T I C L E I N F O}

Article history:

Available online 27 May 2015

\section{Keywords:}

Annual maximum flood

Dramatic decrease

Climate variability

Human activity

Yellow River

\begin{abstract}
A B S T R A C T
Flooding in the Yellow River basin (YRB) has changed significantly over the last few decades because of climate change and human activities. Determining how the flooding changed and identifying the main driving factors of flood change is crucial to flood risk assessment and water resources planning. However, few studies have been conducted, especially in the whole YRB. To fill this gap, we investigate the spatial and temporal change of the annual maximum flood (AMAXF) in the YRB using observed data from 32 key hydrological stations (including 15 mainstream stations and 17 tributary stations). The Mann-Kendall test combined with trend index method is used to evaluate the trend in precipitation and AMAXF. The trend results indicate the AMAXF over the whole basin is dominated by decreasing trends: $72 \%$ of the stations exhibit significant decreasing trends (at 0.1 significance level) and $22 \%$ of the stations show no significant decreasing trends in the AMAXF. Both flood trends and abrupt change time exhibit obvious regional differences: the flood decreases is more pronounced in the midstream basins than in the headwater of the basin; the abrupt changes mainly occurred in the early 1990s for the upper reaches, and in the late 1990s for the middle reaches. To investigate the causes of flood change, the trends of precipitation extremes are analyzed in relation to the trends of peak floods. The analysis reveals that the decreasing precipitation extremes only results in the AMAXF reduction in the upstream basin. The decreasing AMAXF in the midstream and downstream of the basin are mainly attributable to the impacts of human activities (mainly including dam construction and soil conservation practices). In general, anthropogenic impacts play an increasingly important role in the AMAXF changes in the YRB. According to the possible changes in forcing factors, the AMAXF over the whole basin is expected to further decrease in the near future. However, there are still large flood risks in the tributary basins due to the collapse of check dams caused by extreme storms.
\end{abstract}

(c) 2015 Elsevier Ltd and INQUA. All rights reserved.

\section{Introduction}

Flooding is one of the most common hazards and causes property damage and deaths worldwide. The occurrence and variability of flooding is a complex and dynamic process and is affected by various factors, including extreme precipitation, land use practices, dam construction, vegetation properties and soil type. In recent decades, precipitation intensity, frequency and type has changed along with climate warming. Human activities have substantially altered the relationship between rainfall and runoff. The combination of climate change and human activities has caused

\footnotetext{
* Corresponding author.

E-mail address: liaoxfxm@163.com (X. Liu).
}

significant changes in flood trends in many regions around the world (Milly et al., 2008; Zhang et al., 2011b; Ishak et al., 2013). Changes in flood trends create challenges when assessing and managing flood risk. Understanding the spatial and temporal variability of flood trends is helpful for coping with the challenges.

Many studies have investigated the spatial and temporal variability of flood trends worldwide. Petrow and Merz (2009) analyzed the flood trends at 145 stations in Germany and found that flood magnitude increased at many stations. Cunderlik and Ouarda (2009) identified decreasing trends for the magnitudes of snowmelt flood in Canada over the past three decades. McCabe and Wolock (2002) revealed that few gauges had significant trends in flood magnitude in the United States. Kundzewicz et al. (2005) and Svensson et al. (2005) detected the trends in flood magnitudes on a global scale and concluded that flood magnitudes did not present 
significant trends globally. In these studies, the annual maximum flood (AMAXF) was used as the indictor for flood trend analyses (Adamowski and Bocci, 2001; Franks, 2002; Petrow and Merz, 2009; Bormann et al., 2011). The results of these studies showed that the changes of the AMAXF have regional differences.

The Yellow River is the second-longest river in China and the sixth-longest river in the world. It covers an area of approximately $742,443 \mathrm{~km}^{2}$ and supports approximately $30 \%$ of China's population (McVicar et al., 2007; Xu et al., 2009a). The Yellow River is characterized by a high sediment load, accounting for approximately $6 \%$ of the global sediment discharge to the ocean (Milliman and Meade, 1983; Saito et al., 2001). Historically, the Yellow River was the one of the most flood-prone rivers in China. Frequent flood hazards in the Yellow River basin (YRB) have resulted in a large amount of deaths and property damage (Wang et al., 2007a). Over the last 50 years, the YRB has undergone unprecedented changes in land use. Numerous dams and reservoirs have been constructed to control floods and generate power. In addition, a series of soil conservation practices (SCP) have been implemented to reduce soil erosion (Huang and Zhang, 2004; Wang et al., 2006; Yang et al., 2008). The annual precipitation has also changed significantly in many sub-basins of the YRB (Xu et al., 2009a; Dong et al., 2011; Wang et al., 2012). As a result, significant changes in streamflow were observed in the YRB (Wang et al., 2006). Previous studies mainly focused on the changes in annual streamflow (Yang et al., 1998; Fu et al., 2004; Liu et al., 2008; Tang et al., 2008; Yang et al., 2009), while limited attention has been paid to flood trends. Studies about flood trends in the YRB focused on a single or a few gauges (Kang et al., 2001; Xu et al., 2009a; Yao et al., 2011). In this study, we investigate the spatial and temporal changes of the AMAXF for the whole YRB and analyze the reasons for the changes in floods.

\section{Data and methods}

\subsection{Data}

The runoff records at 32 key hydrological stations in the YRB were provided by the Yellow River Hydrological Bureau. Each station has at least 50 years of hydrological data. 22 of 32 stations are located in the middle reaches of the Yellow River, historically flood-prone (Xu et al., 2009a). Detailed information about the stations is shown in Table 1 . The daily precipitation records from 79 national meteorological stations in the YRB were collected from the China Meteorological Data Sharing Service System. The datasets were checked for completeness and consistency before trend analyses. The spatial distributions of the hydrological and meteorological stations are shown in Fig. 1.

\subsection{Trend test method}

In this study, the non-parametric Mann-Kendall (M-K) test (Mann, 1945; Kendall, 1975) combined with the trend index (TI) method (Kundzewicz et al., 2005; Svensson et al., 2005) are used for trend analyses. The $\mathrm{M}-\mathrm{K}$ test has been commonly used for trend detection because of its robustness for non-normally distributed data (Yue et al., 2002; Hamed, 2008). However, using the M-K test, it is hard to reflect the trend magnitude of a time series. Therefore, the results of the $\mathrm{M}-\mathrm{K}$ test are further stated using the TI method to obtain the trend magnitude of a time series (Kundzewicz et al., 2005), which is defined as:

$T I=\left\{\begin{array}{l}100-p \quad \text { for postitive trends } \\ -(100-p) \text { for negative trends }\end{array}\right.$

where $p$ is the significance level calculated by the $\mathrm{M}-\mathrm{K}$ test. The value of TI is always between $-100 \%$ and $100 \%$. A positive value of TI indicates an upward trend, and a negative value indicates a downward trend. The larger the absolute value of TI, the stronger the trend magnitude (Kundzewicz et al., 2005). Compared to traditional methods, such as Sen's slope (Sen, 1968; Hirsch et al., 1982) and linear slope, the TI is not affected by the value of a time series and can better describe the relative change of a time series. Thus, it is widely used in meteorology and hydrology (Svensson et al., 2005; Hirsch and Ryberg, 2012).

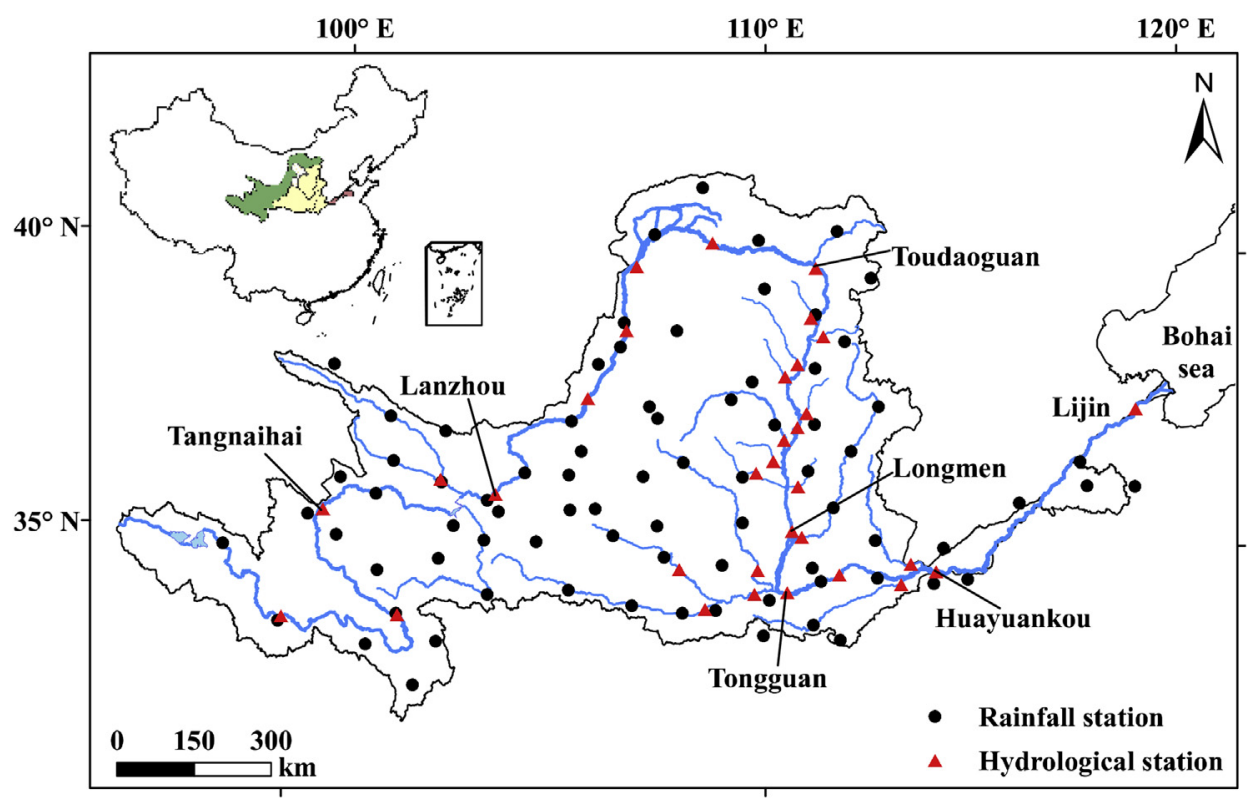

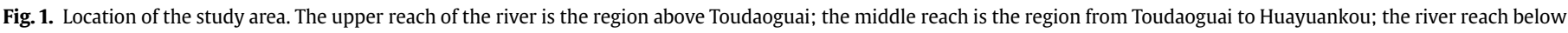
the Huayuankou is the lower reach of the Yellow River. 


\subsection{Abrupt change detection}

The sequential version of the $\mathrm{M}-\mathrm{K}$ test (Mann, 1945; Kendall, 1975 ) is used to analyze the abrupt change point of the AMAXF series. For the sequential time series $x_{1}, x_{2}, \ldots x_{n}, m_{i}$ is the number of later terms in the series whose values exceed $x_{i}$. The $\mathrm{M}-\mathrm{K}$ rank statistic $d_{k}$ is calculated as follows:

$d_{k}=\sum_{i=1}^{k} m_{i} \quad(2 \leq k \leq n)$

The expected value $E\left(d_{k}\right)$ and variance $\operatorname{Var}\left(d_{k}\right)$ are estimated as follows:

$\left\{\begin{array}{l}E\left(d_{k}\right)=\frac{k(k-1)}{4} \\ \operatorname{Var}\left(d_{k}\right)=\frac{k(k-1)(2 k+5)}{72} \quad(2 \leq k \leq n)\end{array}\right.$

The test statistic $U\left(\mathrm{~d}_{k}\right)$ is calculated using the following formula:

$U\left(\mathrm{~d}_{k}\right)=\frac{d_{k}-E\left(d_{k}\right)}{\sqrt{\operatorname{Var}\left(S_{k}\right)}} \quad(1 \leq k \leq n)$

The terms of $U\left(\mathrm{~d}_{k}\right)(1 \leq k \leq n)$ constitute a forward sequence curve $\left(C_{1}\right)$. The same method is then applied to the inversed series and obtains a backward sequence $\left(C_{2}\right)$. The intersection of the $C_{1}$ and $\mathrm{C}_{2}$ curves is regarded as the abrupt change point.

Table 1

Selected runoff gauges in the YRB; "M" indicates the mainstream gauge, "T" indicates the tributary gauge.

\begin{tabular}{|c|c|c|c|c|c|}
\hline Station & Longitude & Latitude & Series & $\begin{array}{l}\text { Drainage } \\
\text { area }\left(\mathrm{km}^{2}\right)\end{array}$ & $\mathrm{M} / \mathrm{T}$ \\
\hline Jimai & 99.64 & 33.78 & 1958-2010 & 45,019 & M \\
\hline Maqu & 102.10 & 33.98 & 1959-2010 & 86,048 & M \\
\hline Tangnaihai & 100.15 & 35.50 & $1956-2010$ & 121,972 & M \\
\hline Minhe & 102.80 & 36.33 & $1955-2010$ & 15,342 & $\mathrm{~T}$ \\
\hline Lanzhou & 103.82 & 36.07 & $1956-2010$ & 222,551 & M \\
\hline Qingtongxia & 106.00 & 37.90 & 1956-2010 & 275,010 & M \\
\hline Shizuishan & 106.78 & 39.15 & 1956-2010 & 309,146 & M \\
\hline Bayingaole & 107.02 & 40.19 & $1973-2010$ & 314,000 & M \\
\hline Sanhuhekou & 108.46 & 40.37 & $1955-2010$ & 347,909 & M \\
\hline Toudaoguai & 111.07 & 40.27 & $1954-2010$ & 367,898 & M \\
\hline Huangfu & 111.08 & 39.28 & $1954-2010$ & 3175 & $\mathrm{~T}$ \\
\hline Qiaotou & 111.13 & 38.93 & 1956-2010 & 2854 & $\mathrm{~T}$ \\
\hline Wenjiachuan & 110.77 & 38.47 & $1954-2010$ & 8645 & $\mathrm{~T}$ \\
\hline Gaojiachuan & 110.48 & 38.25 & $1955-2010$ & 3253 & $\mathrm{~T}$ \\
\hline Linjiaping & 110.87 & 37.67 & 1954-2010 & 1873 & $\mathrm{~T}$ \\
\hline Wupu & 110.72 & 37.45 & $1954-2010$ & 433,514 & M \\
\hline Dingjiagou & 110.25 & 37.55 & $1959-2010$ & 23,422 & $\mathrm{~T}$ \\
\hline Baijiachuan & 110.42 & 37.23 & $1956-2010$ & 29,662 & $\mathrm{~T}$ \\
\hline Ganguyi & 109.80 & 36.67 & $1954-2010$ & 5891 & $\mathrm{~T}$ \\
\hline Daning & 110.72 & 36.45 & $1955-2010$ & 3992 & $\mathrm{~T}$ \\
\hline Longmen & 110.58 & 35.67 & $1956-2010$ & 497,552 & M \\
\hline Hejin & 110.80 & 35.57 & $1954-2010$ & 38,728 & $\mathrm{~T}$ \\
\hline Jingcun & 108.13 & 35.00 & 1960-2010 & 40,281 & $\mathrm{~T}$ \\
\hline Xianyang & 108.7 & 34.32 & $1954-2010$ & 46,827 & $\mathrm{~T}$ \\
\hline Huaxian & 109.76 & 34.59 & $1955-2010$ & 106,498 & $\mathrm{~T}$ \\
\hline Zhuangtou & 109.83 & 35.00 & 1955-2010 & 25,154 & $\mathrm{~T}$ \\
\hline Tongguan & 110.30 & 34.62 & 1954-2010 & 682,144 & M \\
\hline Sanmenxia & 111.37 & 34.82 & 1954-2010 & 688,421 & M \\
\hline Heishiguan & 112.93 & 34.72 & 1954-2010 & 18,563 & $\mathrm{~T}$ \\
\hline Wushe & 113.17 & 35.07 & $1950-2010$ & 12,880 & $\mathrm{~T}$ \\
\hline Huayuankou & 113.65 & 34.92 & $1952-2010$ & 730,036 & M \\
\hline Lijin & 118.30 & 37.52 & $1950-2010$ & 751,869 & M \\
\hline
\end{tabular}

\section{Results}

\subsection{Trend analysis and abrupt change detection}

AMAXF at 23 out of 32 stations exhibits significant decreasing trends at the $5 \%$ significant level, accounting for $72 \%$ of the total number of the stations (Fig. 2a). Seven stations display no significant decreasing trends, and two stations have no significant increasing trends. Overall, the AMAXF over whole basin is dominated by decreasing trends. For the spatial variation, the AMAXF decreased significantly in the midstream and downstream basins, decreased slightly but not significantly in the headwater of the basin. Additionally, the decrease magnitudes in the mainstream stations are larger than those in the tributary stations: $80 \%(12 / 15)$ of the mainstream stations are characteristic by significant decreasing trends, while $65 \%(11 / 17)$ of the tributary stations exhibit significant decreasing trends. The changes in the AMAXF at eight representative stations are shown in Fig. 3. Abrupt change detection indicates that abrupt changes occurred in 21 out 32 stations. Among the 21 stations, 19 stations have one abrupt change and two stations have two abrupt changes (Fig. 2b). The occurrence time of abrupt change has spatial and temporal differences in the YRB. Most of the abrupt changes in the upper reaches occurred in the early 1990s, while the abrupt changes in the middle reaches occurred mainly in the late 1990s. In addition, the occurrence times of abrupt changes at the tributary stations are more scattered than those from the mainstream stations.

\subsection{Reasons for the decreases in the AMAXF in the YRB}

Changes in extreme precipitation and land use/cover changes (LUCC) are regarded as two main contributors to changes in floods worldwide (Douglas et al., 2000; Jain and Lall, 2000; Pinter et al., 2006; Cunderlik and Ouarda, 2009). In this study, we investigate the impacts of extreme precipitation changes and human activities on the changes in the AMAXF in different regions of the YRB.

\subsubsection{Impacts of changes in extreme precipitation on flooding}

The floods in the Yellow River basin are usually caused by one day or several consecutive days of heavy rainfall (Ran et al., 2000; Yao et al., 2011). We referred to the 27 core climate extreme indices recommended by World Meteorological Organization (Zhang et al., 2011a) and chose the Rmax-1day and R20 as the two indices of extreme precipitation to analyze the changes in precipitation extremes. Rmax-1day is defined as the annual maximum daily precipitation and the R20 is defined as the number of days with daily precipitation totals above or equal to $20 \mathrm{~mm}$. We evaluated trends of Rmax-1day and R20 over two time periods (1960-2011 and 1990-2011) and found inconsistent trends for the two periods Fig. 4). During the period from 1960 to 2011, the spatial distribution characteristics of trends in the two indices are similar. Both indices have nonsignificant decreasing trends at most stations. The two indices in the upper and lower reaches feature mixed negative and positive trends, whereas in the middle regions are dominated by negative trends (Fig. 4a and b). The 1990-2011 trends show differences from the trends of 1960-2011. Two indices over the whole basin are dominated by nonsignificant positive trends. The two indices in the upper reaches present nonsignficant positive trends at most stations, and in the middle and lower reaches are characterized by mixed negative and positive trends (Fig. 4c and d).

In the upper reaches (above Tangnaihai station), the impacts of human activities are limited (Zheng et al., 2009). The change in extreme precipitation is considered to be the main driving factor of flood change. The AMAXF and extreme precipitation demonstrate 



Fig. 2. Trend of AMAXF (a) and abrupt change (b) for 32 key runoff stations, 1960-2010. Abrupt change year has been simplified as 98 for 1998,01 for 2001.

consistent trend over the two periods in this region (Figs. 4 and 5). In the middle YRB, however, the changes in the AMAXF are inconsistent with changes in extreme precipitation in the period of 1990-2010. Two indices of extreme precipitation are dominated by nonsignificant increase trends (Fig. 4c and d), whereas the AMAXF still present significant decreasing trends at most stations (Fig. 5). The inconsistent changes between extreme precipitation and the AMAXF indicate that decreasing trends in the AMAXF are mainly caused by human activities rather than extreme precipitation in the middle YRB.

\subsubsection{Impacts of large reservoirs on AMAXF reduction}

The construction of reservoirs is the most direct way to reduce peak discharge during flood season (Wang et al., 2006). Since the 1950s, more than 3100 reservoirs have been built in the YRB, with a total storage capacity of $57.4 \mathrm{~km}^{3}$, which is approximately equal to the mean annual natural discharge of the YRB (Li and Yang, 2004; Wang et al., 2006). Reservoirs with larger storage capacities have more obvious effect on peak flow reduction. By the end of 2010, nine reservoirs along the Yellow River had storage capacities greater than $1.0 \mathrm{~km}^{3}$, of which four have a storage capacity greater than $5.0 \mathrm{~km}^{3}$. The four large reservoirs are Liujiaxia (LJX), Longyangxia (LYX), Sanmenxia (SMX) and Xiaolangdi (XLD), and the spatial distribution of the four reservoirs is shown in Fig. 6. These large dams have significantly changed the downstream flood processes. The impacts can be reflected by the ratio (RA) between the AMAXF at a downstream station and the AMAXF at the upstream station of the reservoir.

The RA exhibited a significantly decreasing trend since the LJX reservoir opened in 1968 (Fig. 7). Abrupt change at the Lanzhou station and at several downstream gauges most likely resulted from the dam operation at the two reservoirs (Fig. 4). Thus, the operation of large dams in the headwater of the river is the major cause of the AMAXF reduction for the gauges below dams. The impacts of dams on downstream floods are gradually weakened with increasing distance from the dams.

The other two large reservoirs, SMX and XLD, are located in the river segment between Tongguan to Huayuankou (Fig. 6). They play a vital role in reducing the flood risk in downstream regions (Yang et al., 2008). The SMX reservoir was completed in 1960 with a storage capacity of $9.7 \mathrm{~km}^{3}$ (YRCC, 2008). The SMX reservoir resulted in severe sediment deposition and was forced to operate at a low storage level in flood seasons since 1962 to balance the sediment inflow and outflow (Wang et al., 2005, 2007b). During operation, the flood control function of the dam was weakened. There is no noticeable decrease in the RA since the operation of the SMX reservoir (Fig. 7b). 

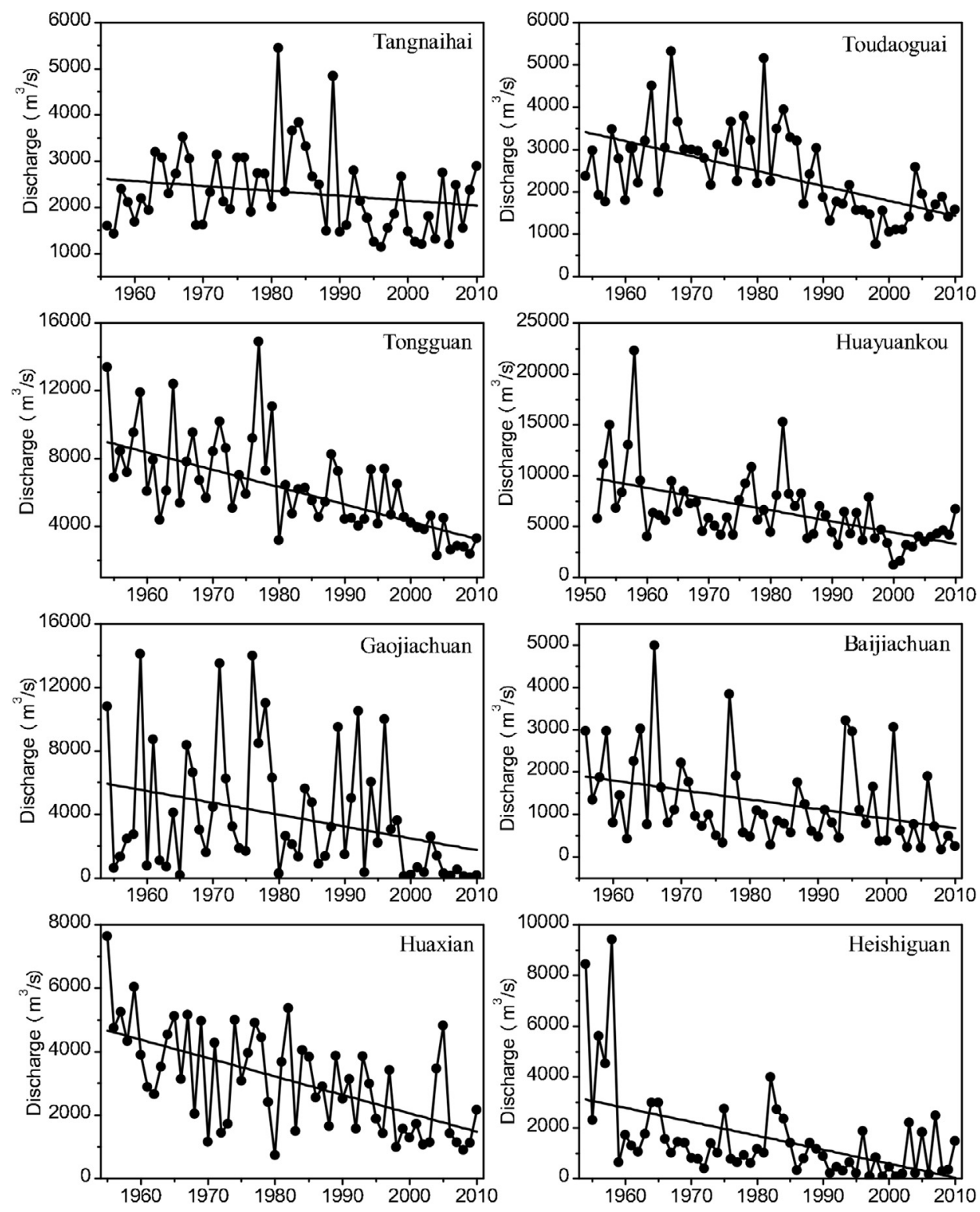

Fig. 3. The change of the AMAXF at eight representative stations.

Since the operation of the XLD reservoir in 2001, the Yellow River Conservancy Commission (YRCC) had the ability to regulate water-sediment to reduce the sediment siltation on the downstream riverbed and reservoirs. Water-sediment regulation is a reservoir operation scheme that releases the water storage in XLD, SMX and other small reservoirs to generate "man-made flood" to scour the riverbed (Ran et al., 2000; Li and Sheng, 2011). From 2002 to 2010 , more than 10 water-sediment regulation schemes were conducted and resulted in a significant increase in the AMAXF for the downstream gauges of the dam since 2002 (Fig. 7b). The function of the XLD reservoir was to reduce peak flow, but there has not been a large flood since completion of the reservoir, so its role has not been fully demonstrated. According to the original design, however, the dam can increase the flood return period downstream from less than 100 years -500 years.

\subsubsection{The impacts of soil conservation practices (SCP) on flood reduction}

The middle reaches of the Yellow River pass through the Loess Plateau, which is a major sediment source for the river.
Approximately $90 \%$ of the total river sediment comes from this region (Milliman et al., 1987; Tang et al., 2008; Yang and Liu, 2011). Soil and water loss caused serious degradation of the ecoenvironment in the Loess Plateau, and led to sediment siltation on the downstream riverbed and reservoirs. Since the late 1970s, numerous SCP (e.g., afforestation, grass-planting, level terraces and check dam) have been implemented to reduce soil erosion and improve the environment (Hassan et al., 2008; Zhang et al., 2008; Li et al., 2010). The percentage of SCP areas accounting for the total soil erosion area in the middle YRB has increased from $13.2 \%$ in 1978 to 41.1\% in 1997 (Gao et al., 2011). A nationwide ecological recovery program, the "Grain for Green Project" (GGP) began in 1999, which has greatly increased the vegetation coverage in the Loess Plateau (Fig. 8 and Table 2). The SCP can effectively reduce the runoff and sediment generation by intercepting precipitation, increasing water infiltration and delaying surface runoff (Huang and Zhang, 2004; Valentin et al., 2008; Miao et al., 2011). Some studies indicated that the increasing SCP were mainly responsible for the peak flow reduction in major tributaries of the middle YRB (Xu and Chen, 2000; Kang et al., 2001; Ran et al., 2004). 

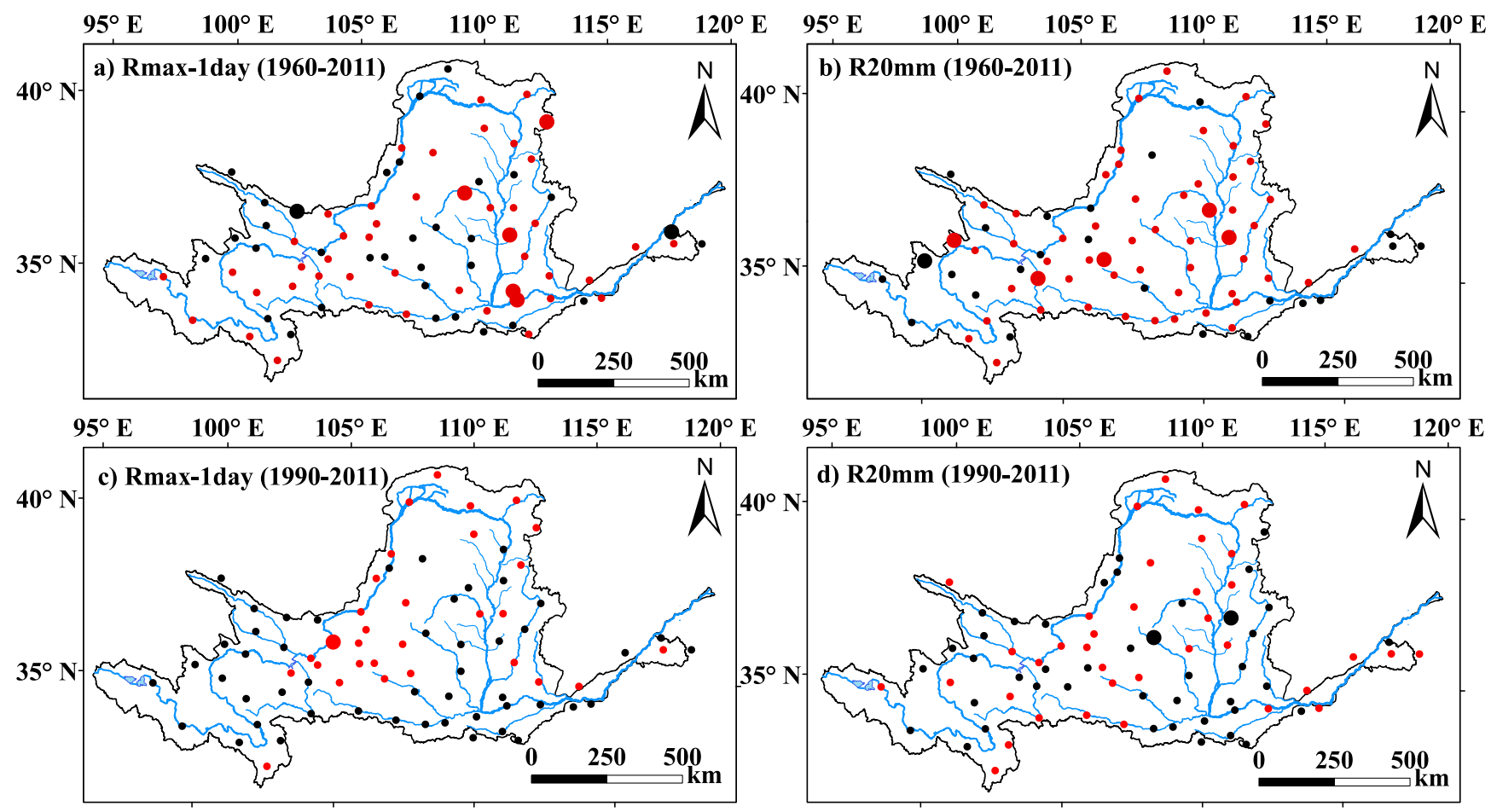

- Significant decrease - Nonsignificant decrease - Nonsignificant increase $\bullet$ Significant increase

Fig. 4. Trend of extreme precipitation over the Yellow River basin.



Fig. 5. Trend of the AMAXF in 1990-2010.

To quantitatively assess the effects of SCP on reducing peak flow since the implication of GPP, we analyzed the relationship between the AMAXF and corresponding areal precipitation in two representative sub-basins in the middle YRB (Fig. 9). Under similar areal precipitation, the differences in AMAXF before and after the implication of GPP are considered approximately as the AMAXF changes caused by SCP. The results indicate that approximate $20 \%$ $80 \%$ reduction in AMAXF can be attributed to the impacts of SCP. As the vegetation coverage increases, the effects of SCP on reducing peak flows are likely more significant. Moreover, the results of abrupt change detection further reveal that abrupt changes are likely to be associated with the SCP implementation (Fig. 2b).

\section{Discussion}

\subsection{Possible future changes in flood in the $Y R B$}

Changes in extreme precipitation and human activities are the two main factors altering flood characteristics. Changes in floods in the near future are mainly dependent on the changes in the two factors. Based on the trends of the two factors, the AMAXF is likely to further decrease in the YRB. First, with increasing vegetation coverage, the SCP will have more significant influences on reducing peak flow. Second, with the increasing energy demand, China would develop hydropower in the YRB (Kahrl, 2012; Li and Wang, 




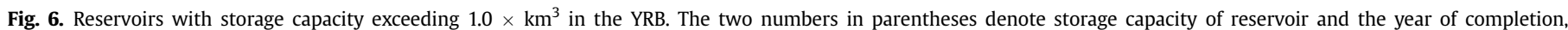
respectively. Triangles represent hydrological stations.
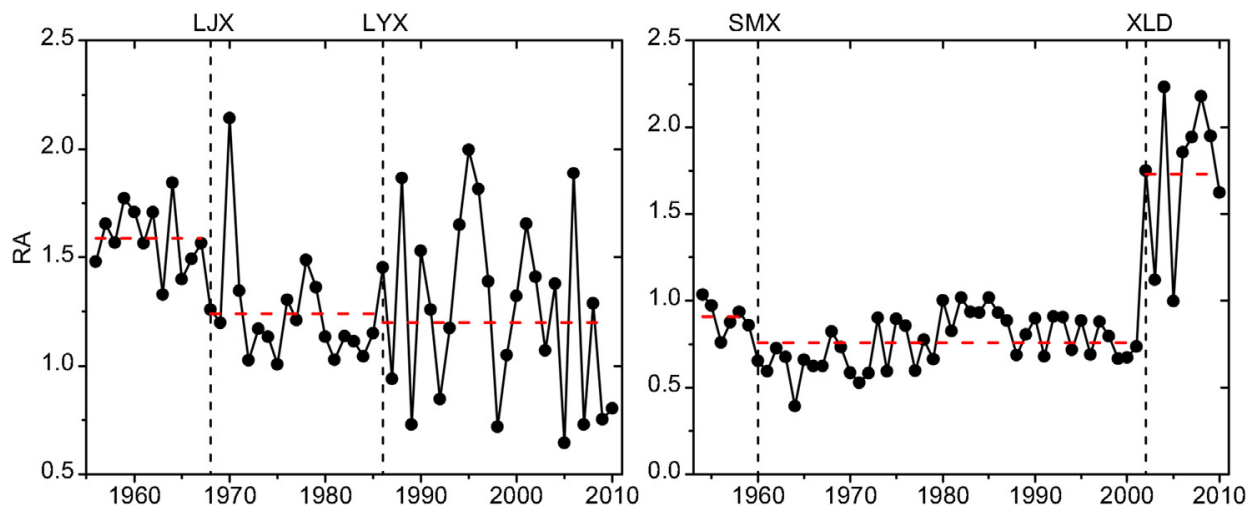



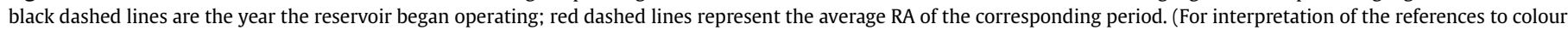
in this figure legend, the reader is referred to the web version of this article.).

2012; Zhou et al., 2012). As a result, a large number of hydropower projects would be constructed on the Yellow River (Huang et al., 2006). These projects can reduce floodwater during flood seasons. Finally, although many studies indicated that future precipitation in the YRB is projected to increase according to the outputs of various general circulation models (GCMs) (Zhang et al., 2006; Shi et al., 2009; Xu et al., 2011; Li et al., 2012; Sun et al., 2012), considerable uncertainties exist in the GCMs. It is hard to offset the reduction effects of human activities on flooding, even if an increasing trend is present for future extreme precipitation. Therefore, human activities are still a major driving factor for the future change in the AMAXF in the YRB.

\subsection{Facing decreasing peak flow in the YRB, should we revise the} flood design criteria of hydraulic structures to reduce cost?

The designed flood estimations are the basis for building flood protection measures and performing integrated flood management to protect people's lives and property (Rogger et al., 2012). An underestimation of flood risk may result in damage, whereas an overestimation can increase the design costs. Traditionally, flood estimations and flood designs are generally based on the assumption that the flood regime is stationary (Petrow and Merz, 2009; Luo et al., 2012). The assumption has been questioned recently because of the natural climate variability and the potential influence of human activities on the hydrological cycle (Milly et al., 2008). Many studies have emphasized the need to take nonstationary time series into consideration for designing flood estimations (Strupczewski et al., 2001; Cunderlik and Burn, 2003; El Adlouni et al., 2007; Leclerc and Ouarda, 2007).

Facing the decreasing AMAXF in the YRB, should we revise the flood design criteria to reduce cost? We think that it is not wise to do that due to some potential flood risks in the YRB. First, although the dams along the river can effectively reduce the downstream flood risk with large water storage capacities, the storage capacities of these large reservoirs are continuously shrinking because of severe sediment deposition. The XLD reservoir, for example, had a volume of accumulated sediment up to $2.58 \mathrm{~km}^{3}$ from 1999 to 2009 (Wang et al., 2011), implying that the reservoir had lost approximately one fifth of its initial water storage capacity by the 11 th year. The flood control ability of a dam would be weakened with increasing sediment deposition. Second, the check dams, as temporary structures, are mainly made of cheap and accessible materials such as loess, rocks, and sandbags in the Loess Plateau. More 


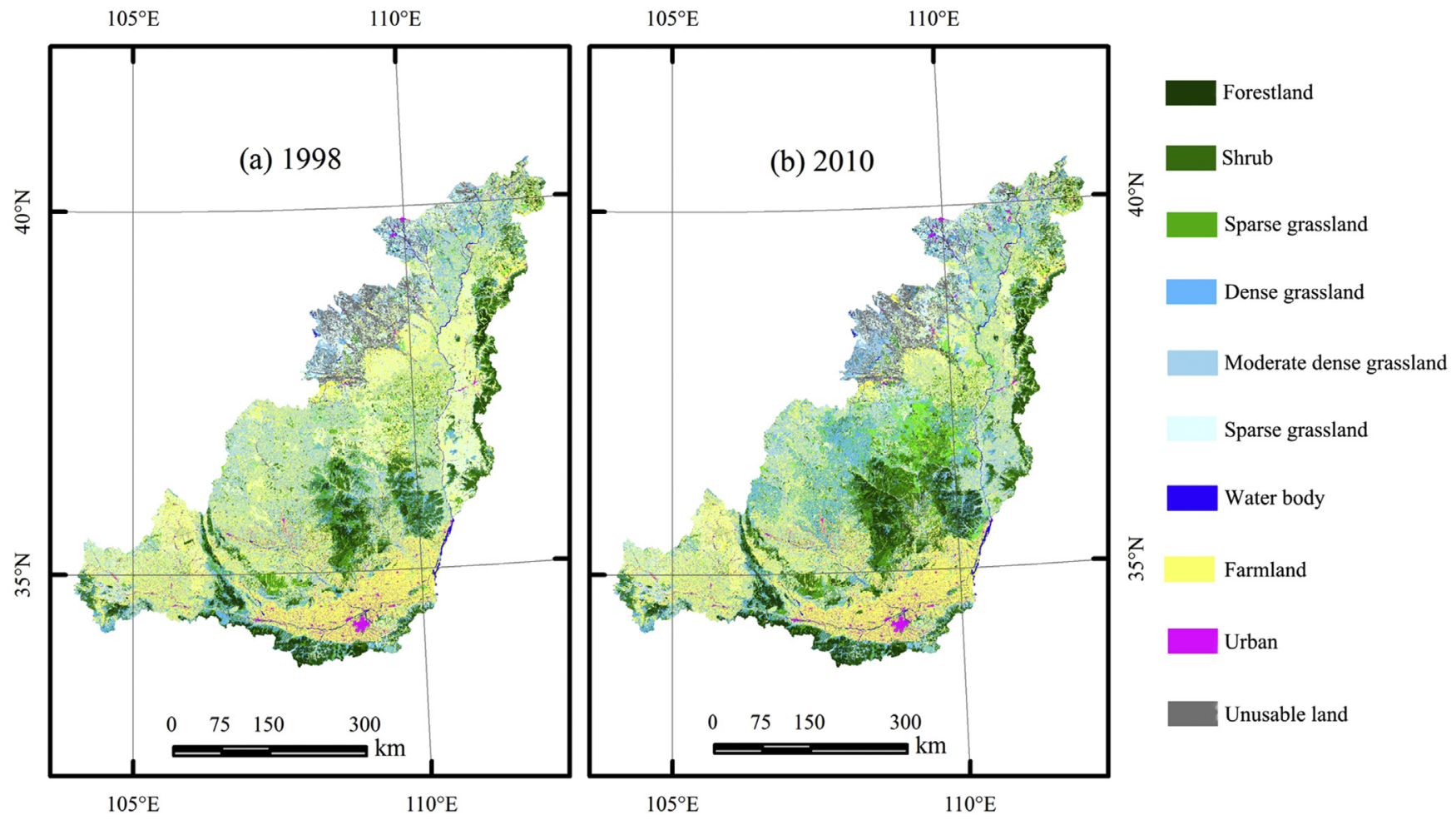

Fig. 8. Land use map of the middle reach of the Yellow River in 1998 (a) and 2010 (b). (Luo et al., 2014).

Table 2

Area of soil conservation practices in Tongdaoguai-Longmen sub-basins.

\begin{tabular}{cccccc}
\hline \multirow{2}{*}{ Year } & \multicolumn{5}{l}{ Area of soil conservation practices $\left(\mathrm{km}^{2}\right)$} \\
\cline { 2 - 6 } & Level terrace & Afforestation & Grass-planting & Check dam & Total \\
\hline 1959 & 331 & 1513 & 357 & 28 & 2229 \\
1969 & 1060 & 3140 & 383 & 121 & 4704 \\
1979 & 2130 & 7730 & 730 & 364 & 10,954 \\
1989 & 3020 & 12,070 & 1680 & 515 & 17,285 \\
1999 & 3466 & 15,391 & 3209 & 486 & 22,552 \\
2006 & 4597 & 26,160 & 5673 & 666 & 37,096 \\
\hline
\end{tabular}

Data source: Ran et al. (2000) and Yao et al. (2011).

than half of check dams were constructed before the 2000s (Fig. 10). After many years of erosion and siltation, these old check dams are easily destructible by heavy rainfall. Some studies indicated that the check dams could reduce effectively the normal flood but not extreme flood (Kang et al., 2001; Zhang et al., 2004; Chen et al., 2005). Once the dam collapses, the flood flows rapidly and returns to the previous state before implementing the SCP. A case can be identified in the flood observation records of the Yanchuan station in Qinjianhe River (Fig. 11). In July 2002, unusually heavy rainfall occurred in the upper basin and resulted in a severe flooding. The peak flow in Yanchuan station reached to $5540 \mathrm{~m}^{3} / \mathrm{s}$, which is the second largest flood of record. More than 80 check dams were destroyed during the flooding event (Chen et al., 2005), which aggravated considerably the flood magnitude and offset the effect of other SCP on reduction of flooding. Finally, numerous studies reported that the rainfall extremes have increased around the world (Alexander et al., 2006; Allan and Soden, 2008; Liu et al., 2009; Sun and Ao, 2013). Extreme precipitation events are likely to increase in the YRB according to multiple GCMs projections (Xu et al., 2009b; Li et al., 2012; Wu et al., 2015).
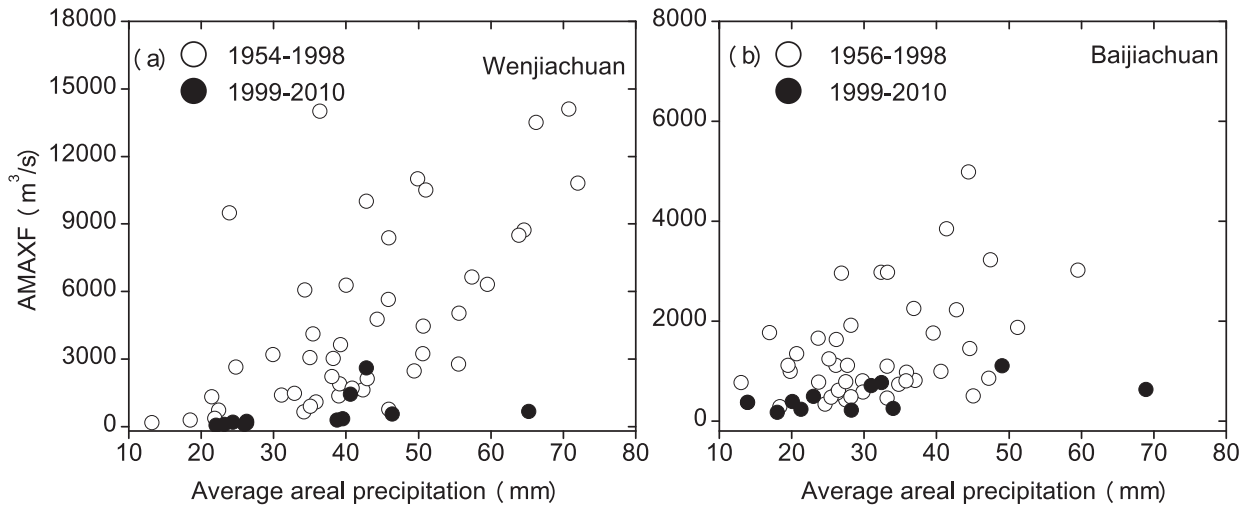

Fig. 9. Relationship between AMAXF and corresponding areal precipitation at Wenjiachuan and Baijiachuan stations. 


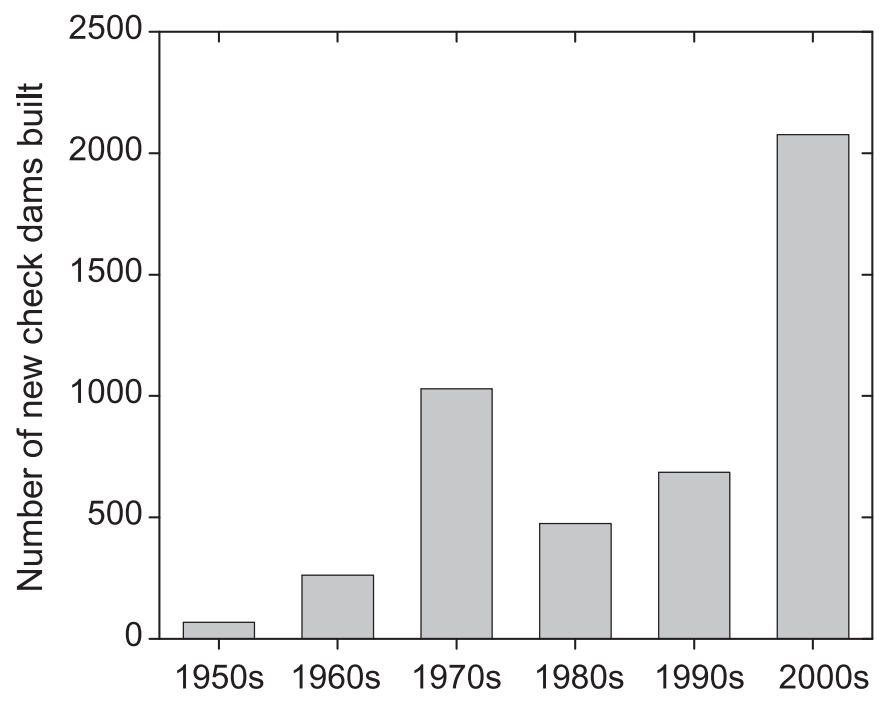

Fig. 10. Number of new check dams built from 1950s to 2000s.


Fig. 11. (a) Changes of the AMAXF at Yanchuan station. Dashed lines represent the average AMAXF. (b) Relationship between AMAXF and corresponding areal precipitation at Yanchuan station.

\section{Conclusions}

In this study, we investigated the spatial and temporal variations of flood in the YRB and analyzed the natural/anthropogenic influences on flood trends. The AMAXF series from 32 key gauging stations over the YRB were chosen as the flood indictor for trend analyses. The results showed that most (72\%) gauging stations show significant downward trends in the AMAXF, especially for mainstream gauges in the middle and lower reaches of the river. The decreasing flooding in the YRB is caused by many factors, including reduction in heavy rainfall, dam construction and soil conservation practices, which are considered to be the three main factors. Contribution analyses reveal that decreasing flooding is mainly caused by precipitation reduction in river source regions, dam construction in the region from Lanzhou to Toudaoguai, and the implementation of SCP in tributary regions from Toudaoguai to Tongguan. For these mainstream gauges below Tongguan, the causes of flood reduction are more complex, involving the joint effects of multiple factors. Overall, human activities play an increasing role in stream extreme change in the YRB. Flood in the near future is likely to further reduction because of the changes of various driving factors. However, flooding hazards may still frequently occur, particularly in tributary regions of the river. Further research should be performed to investigate the flood trends using more flood indices and gauges to better understand the change of flood characteristics in the basin.

\section{Acknowledgments}

The authors gratefully acknowledge the assistance of Dr. Luo Ya for sharing the published land use map of the middle reach of the Yellow River. This research was supported by the Natural Science Foundation of China $(41201034,41330529)$, the program for "Bingwei" Excellent Talents in Institute of Geographic Sciences and Natural Resources Research, CAS (Project No.2013RC202) and Chinese Academy of Sciences Visiting Professorship for Senior International Sciences (2013T2Z0014).

\section{References}

Adamowski, K., Bocci, C., 2001. Geostatistical regional trend detection in river flow data. Hydrological processes 15 (18), 3331-3341.

Alexander, L.V., Zhang, X., Peterson, T.C., et al., 2006. Global observed changes in daily climate extremes of temperature and precipitation. Journal of Geophysical Research: Atmospheres 111 (D5), D05109.

Allan, R.P., Soden, B.J., 2008. Atmospheric warming and the amplification of precipitation extremes. Science 321, 1481-1484.

Bormann, H., Pinter, N., Elfert, S., 2011. Hydrological signatures of flood trends on German rivers: flood frequencies, flood heights and specific stages. Journal of Hydrology 404, 50-66.

Chen, J., Zhang, S., Zhao, Y., Wang, G., 2005. Analysis on flood control condictions of soil and water conservation measures in Qinjianhe River basin. Journal of Sediment Research 1, 14-20.

Cunderlik, J.M., Burn, D.H., 2003. Non-stationary pooled flood frequency analysis. Journal of Hydrology 276, 210-223.

Cunderlik, J.M., Ouarda, T.B.M.J., 2009. Trends in the timing and magnitude of floods in Canada. Journal of Hydrology 375, 471-480.

Dong, Q., Chen, X., Chen, T., 2011. Characteristics and changes of extreme precipitation in the Yellow-Huaihe and Yangtze-Huaihe rivers basins, China. Journal of Climate 24, 3781-3795.

Douglas, E., Vogel, R., Kroll, C., 2000. Trends in floods and low flows in the United States: impact of spatial correlation. Journal of Hydrology 240, 90-105.

El Adlouni, S., Ouarda, T., Zhang, X., Roy, R., Bobée, B., 2007. Generalized maximum likelihood estimators for the nonstationary generalized extreme value model. Water Resources Research 43 (3).

Franks, S.W. 2002. Identification of a change in climate state using regional flood data. Hydrology and Earth System Sciences Discussions 6 (1), 11-16.

Fu, G., Chen, S., Liu, C., Shepard, D., 2004. Hydro-climatic trends of the Yellow River basin for the last 50 years. Climatic Change 65 (1), 149-178.

Gao, P., Mu, X.M., Wang, F., Li, R., 2011. Changes in streamflow and sediment discharge and the response to human activities in the middle reaches of the Yellow River. Hydrology and Earth System Sciences 15 (1), 1-10.

Hamed, K.H., 2008. Trend detection in hydrologic data: the Mann-Kendall trend test under the scaling hypothesis. Journal of Hydrology 349, 350-363.

Hassan, M.A., Church, M., Xu, J., Yan, Y., 2008. Spatial and temporal variation of sediment yield in the landscape: example of Huanghe (Yellow River). Geophysical Research Letters 35 (6)

Hirsch, R., Ryberg, K., 2012. Has the magnitude of floods across the USA changed with global CO2 levels? Hydrological Sciences Journal 57 (1), 1-9. 
Hirsch, R.M., Slack, J.R., Smith, R.A., 1982. Techniques of trend analysis for monthly water quality data. Water Resources Research 18 (1), 107-121.

Huang, M., Zhang, L., 2004. Hydrological responses to conservation practices in a catchment of the Loess Plateau, China. Hydrological Processes 18 (10), 1885-1898.

Huang, Q., Xia, Z., Liu, H., 2006. Dynamic calculation of power generation compensation benefits of the Yellow River upstream cascade power stations in different level years. Journal of Hydroelectric Engineering 25 (4), 6-11.

Ishak, E.H., Rahman, A., Westra, S., Sharma, A., Kuczera, G., 2013. Evaluating the non-stationarity of Australian annual maximum flood. Journal of Hydrology 494, 134-145.

Jain, S., Lall, U., 2000. Magnitude and timing of annual maximum floods: trends and large-scale climatic associations for the Blacksmith Fork River, Utah. Water Resources Research 36 (12), 3641-3651.

Kahrl, F., 2012. Energy and environmental policy in China: towards a low carbon economy. Journal of Environmental Policy \& Planning 14 (3), 333-334.

Kang, L., Yao, W., Wang, Y., Wang, G., Wu, Q., 2001. Preliminary of analysis of effect of soil and water conservation on flood in Huangfuchuan watershed. Journal of Soil and Water Conservation 15 (5), 29-33.

Kendall, M.G., 1975. Rank Correlation Methods. Charle Griffin, London.

Kundzewicz, Z.W., Graczyk, D., Maurer, T., et al., 2005. Trend detection in river flow series: 1. Annual Maximum Flow Hydrological Sciences Journal 50 (5).

Leclerc, M., Ouarda, T.B., 2007. Non-stationary regional flood frequency analysis at ungauged sites. Journal of hydrology 343 (3), 254-265.

Li, C., Qi, J., Feng, Z., et al., 2010. Quantifying the effect of ecological restoration on soil erosion in China's Loess Plateau region: an application of the MMF approach. Environmental management 45 (3), 476-487.

Li, C., Yang, Z., 2004. The influence of main reserviors in main stream on annual streamflow, Yellow River. Yellow River 26, 15-16.

Li, G., Sheng, L., 2011. Model of water-sediment regulation in Yellow River and its effect. Science China Technological Sciences 54 (4), 924-930.

Li, J., Wang, X., 2012. Energy and climate policy in China's twelfth five-year plan: a paradigm shift. Energy Policy 41, 519-528.

Li, Z., Zheng, F.-L., Liu, W.-Z., Jiang, D.-J., 2012. Spatially downscaling GCMs outputs to project changes in extreme precipitation and temperature events on the Loess Plateau of China during the 21st Century. Global and Planetary Change $82-83,65-73$

Liu, Q., Yang, Z., Cui, B., 2008. Spatial and temporal variability of annual precipitation during 1961-2006 in Yellow River Basin, China. Journal of Hydrology 361, 330-338.

Liu, S.C., Fu, C., Shiu, C.-J., Chen, J.-P., Wu, F., 2009. Temperature dependence of global precipitation extremes. Geophysical Research Letters 36 (17), L17702.

Luo, J., Wang, E., Shen, S., Zheng, H., Zhang, Y., 2012. Effects of conditional parameterization on performance of rainfall-runoff model regarding hydrologic nonstationarity. Hydrological Processes 26 (26), 3953-3961.

Luo, Y., Yang, S., Liu, X., et al., 2014. Land use change in the reach from Hekouzhen to Tongguan of the Yellow River during 1998-2010. Journal of Geographical Sciences 69 (1), 42-53.

Mann, H.B., 1945. Nonparametric tests against trend. Econometrica: Journal of the Econometric Society 245-259.

McCabe, G.J., Wolock, D.M., 2002. A step increase in streamflow in the conterminous United States. Geophysical Research Letters 29 (24), 2185.

McVicar, T.R., Van Niel, T.G., Li, L., et al., 2007. Spatially distributing monthly reference evapotranspiration and pan evaporation considering topographic influences. Journal of Hydrology 338 (3), 196-220.

Miao, C., Ni, J., Borthwick, A.G.L., Yang, L., 2011. A preliminary estimate of human and natural contributions to the changes in water discharge and sediment load in the Yellow River. Global and Planetary Change 76 (3-4), 196-205.

Milliman, J.D., Meade, R.H., 1983. World-wide delivery of river sediment to the oceans. The Journal of Geology 1-21.

Milliman, J.D., Yun-Shan, Q., Mei-e, R., Saito, Y., 1987. Man's influence on the erosion and transport of sediment by Asian rivers: the Yellow River (Huanghe) example. The Journal of Geology 751-762.

Milly, P.C.D., Betancourt, J., Falkenmark, M., et al., 2008. Climate change - stationarity is dead: whither water management? Science 319, 573-574.

Petrow, T., Merz, B., 2009. Trends in flood magnitude, frequency and seasonality in Germany in the period 1951-2002. Journal of Hydrology 371 (1-4), 129-141.

Pinter, N., Ickes, B.S., Wlosinski, J.H., van der Ploeg, R.R., 2006. Trends in flood stages: contrasting results from the Mississippi and Rhine River systems. Journal of Hydrology 331 (3-4), 554-566.

Ran, D. Liu, L., Zhao, L., 2000. The Soil and Water Conservation and the Hydrological Responses in the Middle Reaches of the Yellow River. Yellow River Conservancy Press, Zhengzhou ( in Chinese).

Ran, D., Luo, Q., Liu, B., Wang, H., 2004. Effect of soil-retaining dams on flood and sediment reduction in the middle reaches of the Yellow River. Journal of Hydraulic Engineering 35 (5), 7-13 (in Chinese).

Rogger, M., Kohl, B., Pirkl, H., et al., 2012. Runoff models and flood frequency statistics for design flood estimation in Austria - do they tell a consistent story? Journal of Hydrology 456-457, 30-43.

Saito, Y., Yang, Z., Hori, K., 2001. The Huanghe (Yellow River) and Changjiang (Yangtze River) deltas: a review on their characteristics, evolution and sediment discharge during the Holocene. Geomorphology 41 (2), 219-231.

Sen, P.K., 1968. Estimates of the regression coefficient based on Kendall's tau. Journal of the American Statistical Association 63 (324), 1379-1389.

Shi, Y., Gao, X., Wang, Y., Filippo, G., 2009. Simulation and projection of monsoon rainfall and rain patterns over eastern China under global warming by RegCM3. Atmospheric and Oceanic Science Letters 2 (5), 1-6.
Strupczewski, W., Singh, V., Feluch, W., 2001. Non-stationary approach to at-site flood frequency modelling I. Maximum likelihood estimation. Journal of Hydrology 248, 123-142.

Sun, F., Roderick, M.L., Farquhar, G.D., 2012. Changes in the variability of global land precipitation. Geophysical Research Letters 39 (19), L19402.

Sun, J., Ao, J., 2013. Changes in precipitation and extreme precipitation in a warming environment in China. Chinese Science Bulletin 58 (12), 1395-1401.

Svensson, C., Kundzewicz, W.Z., Maurer, T., 2005. Trend detection in river flow series: 2. Flood and Low-flow Index Series Hydrological Sciences Journal 50 (5).

Tang, Q., Oki, T., Kanae, S., Hu, H., 2008. Hydrological cycles change in the Yellow River Basin during the last half of the twentieth Century. Journal of Climate 21, 1790-1806.

Valentin, C., Agus, F., Alamban, R., et al., 2008. Runoff and sediment losses from 27 upland catchments in Southeast Asia: Impact of rapid land use changes and conservation practices. Agriculture, Ecosystems \& Environment 128 (4), 225-238.

Wang, G., Wu, B., Wang, Z.-Y., 2005. Sedimentation problems and management strategies of Sanmenxia Reservoir, Yellow River, China. Water Resources Research 41 (9), W09417.

Wang, H., Yang, Z., Saito, Y., Liu, J.P., Sun, X., 2006. Interannual and seasonal variation of the Huanghe (Yellow River) water discharge over the past 50 years: connections to impacts from ENSO events and dams. Global and Planetary Change 50, 212-225.

Wang, H., Yang, Z., Saito, Y., et al., 2007a. Stepwise decreases of the Huanghe (Yellow River) sediment load (1950-2005): Impacts of climate change and human activities. Global and Planetary Change 57 (3-4), 331-354.

Wang, T., Chen, S., Ma, H., Zhang, J., 2011. Distribution of deposition in Xiaolangdi Reservoir. Journal of Sediment Research 5, 60-66.

Wang, W., Shao, Q., Yang, T., et al., 2012. Changes in daily temperature and precipitation extremes in the Yellow River basin, China. Stochastic Environmental Research and Risk Assessment 27 (2), 401-421.

Wang, Z.Y., Wu, B., Wang, G., 2007b. Fluvial processes and morphological response in the Yellow and Weihe Rivers to closure and operation of Sanmenxia Dam. Geomorphology 91, 65-79.

Wu, Z., Xiao, H., Lu, G., Chen, J., 2015. Assessment of climate change effects on water resources in the Yellow River basin, China. Advances in Meteorology 2015, 8.

Xu, C., Luo, Y., Xu, Y., 2011. Projected changes of precipitation extremes in river basins over China. Quaternary International 244, 149-158.

Xu, J., li, X., Chen, J., Gao, Y., Li, M., 2009a. The Influence of Water Conservancy Projects on Storm-flood-sediment in the Middle Reaches of Yellow River Basin. Water Conservancy Press, Zhenzhou, China.

Xu, Z., Chen, J., 2000. Analysis of soil and water conservation treatments on runoff in the Middle Yellow River. Yellow River 25 (7), 125-129 (in Chinese).

Xu, Z.X., Zhao, F.F., Li, J.Y., 2009b. Response of streamflow to climate change in the headwater catchment of the Yellow River basin. Quaternary International 208, $62-75$.

Yang, T., Xu, C.-Y., Shao, Q., et al., 2009. Temporal and spatial patterns of low-flow changes in the Yellow River in the last half century. Stochastic Environmental Research and Risk Assessment 24, 297-309.

Yang, T., Zhang, Q., Chen, Y.D., et al., 2008. A spatial assessment of hydrologic alteration caused by dam construction in the middle and lower Yellow River, China. Hydrological Processes 22, 3829-3843.

Yang, Z., Liu, Q., 2011. Response of streamflow to climate changes in the Yellow River basin, China. Journal of Hydrometeorology 12, 1113-1126.

Yang, Z., Milliman, J., Galler, J., Liu, J., Sun, X., 1998. Yellow River's water and sediment discharge decreasing steadily. Eos, Transactions American Geophysical Union 79 (48), 589-592.

Yao, W., Xu, J., Ran, D., 2011. Analysis and Assessment of Variation Characteristics on Water and Sediment in Yellow River Basin. Water Conservancy Press, Zhenzhou, China (in Chinese).

YRCC, 2008. Flood Control Planning. Yellow River Water Conservancy Press, Zhenzhou, China (in Chinese).

Yue, S., Pilon, P., Cavadias, G., 2002. Power of the Mann-Kendall and Spearman's rho tests for detecting monotonic trends in hydrological series. Journal of Hydrology 259, 254-271.

Zhang, S., Kang, S., Zhang, K., 2004. Effect of soil and water conservation on the runoff on the Loess Plateau. Transactions of the Chinese Society of Agricultural Engineering 20 (6), 56-60.

Zhang, X., Alexander, L., Hegerl, G.C., et al., 2011a. Indices for monitoring changes in extremes based on daily temperature and precipitation data. Wiley Interdisciplinary Reviews: Climate Change 2 (6), 851-870.

Zhang, X., Zhang, L., Zhao, J., Rustomji, P., Hairsine, P., 2008. Responses of streamflow to changes in climate and land use/cover in the Loess Plateau, China. Water Resources Research 44.

Zhang, Y., Xu, Y., Dong, W., Cao, L., Sparrow, M., 2006. A future climate scenario of regional changes in extreme climate events over China using the PRECIS climate model. Geophysical Research Letters 33 (24).

Zhang, Z., Chen, X., Xu, C.-Y., et al., 2011b. Evaluating the non-stationary relationship between precipitation and streamflow in nine major basins of China during the past 50years. Journal of Hydrology 409, 81-93.

Zheng, H., Zhang, L., Zhu, R., et al., 2009. Responses of streamflow to climate and land surface change in the headwaters of the Yellow River Basin. Water Resources Research 45.

Zhou, S., Tong, Q., Yu, S., et al., 2012. Role of non-fossil energy in meeting China's energy and climate target for 2020. Energy Policy 51, 14-19. 